13

\title{
Влияние структуры стеклоуглерода на аспектное отношение микроострий матричных автоэмиссионных катодов, изготовленных термохимическим травлением
}

\author{
(С) Л.С. Плешкова, В.И. Шестеркин \\ АО „Научно-производственное предприятие „Алмаз“, \\ 410033 Саратов, Россия \\ ฯ e-mail: shesterkin.v@mail.ru
}

(Поступило в Редакцию 7 декабря 2015 г. В окончательной редакции 18 февраля 2016 г.)

Использование технологии термохимического травления позволило проявить и исследовать структуру стеклоуглерода марки СУ-2000 методом электронной микроскопии. На микро- и наноразмерном уровнях структура стеклоуглерода неоднородна и состоит из полостей неправильной в сечении формы, разделенных перегородками. Данная структура накладывает ограничения на величину аспектного отношения геометрических размеров и плотность упаковки микроострий в матрице при их изготовлении методом термохимического травления.

\section{Введение}

Необходимая для автоэлектронной эмиссии напряженность электрического поля $5 \cdot 10^{7}-1 \cdot 10^{8} \mathrm{~V} / \mathrm{cm}$ на вершинах микроострий определяется геометрическими размерами автоэмиссионной ячейки, напряжениями на ее электродах и аспектным отношением геометрических размеров самих микроострий, которое определяется как отношение высоты микроострия к радиусу кривизны его вершины. Величина аспектного отношения микроострия наиболее критична к изменению радиуса кривизны его вершины [1]. С целью увеличения аспектного отношения микроострий при ограниченных технологических возможностях их формирования с максимально возможной высотой стремятся уменьшить радиус кривизны их вершин. Так, в ячейках Спиндта микроострия из молибдена высотой $\sim 1.5 \mu \mathrm{m}$ имеют радиус кривизны вершины $\sim 10.0 \mathrm{~nm}$, при этом аспектное отношение их геометрических размеров составляет более 100 единиц [2].

Матрицы микроострий из стеклоуглерода формируют термохимическим травлением в среде водорода при температуре $1050-1100^{\circ} \mathrm{C}$ с помощью пленки никеля с отверстиями и последующим плазмохимическим заострением [3]. Микроострия имеют форму прямого усеченного конуса с диаметром основания 7-9 $\mu \mathrm{m}$, высотой $10-12 \mu \mathrm{m}$ и размером вершины $1.5-2.5 \mu \mathrm{m}$. Аспектное отношение микроострий не превышает 15 единиц. Вследствие этого напряжения на управляющей сетке триодных электронных пушек, использующих ячейки
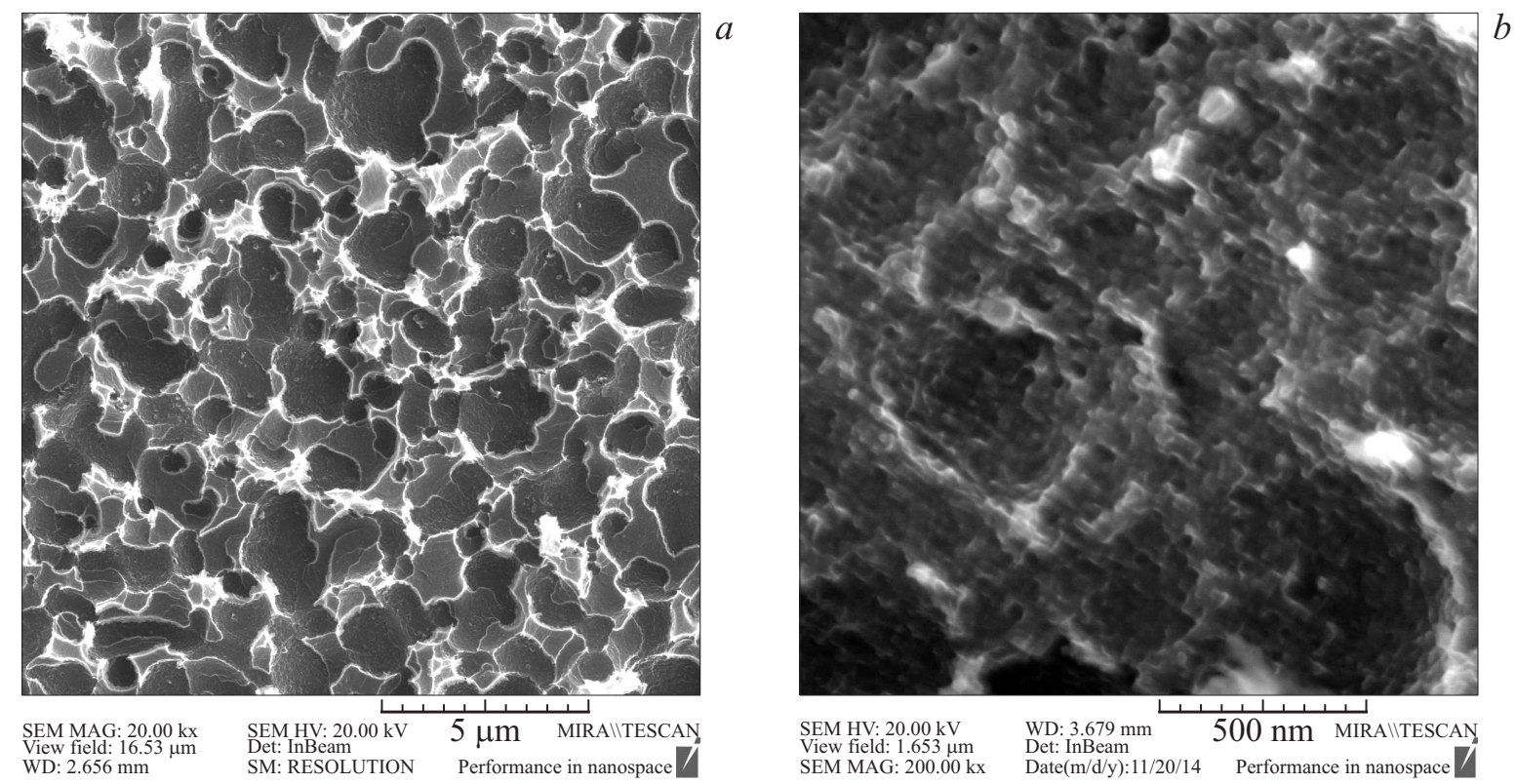

Рис. 1. Поверхность стеклоуглерода марки СУ-2000. $a$ - при 20 000-кратоном увеличении, $b$ - при 200 000-кратоном увеличении. 
с данными микроостриями, составляли единицы киловольт [4].

В настоящей работе методом электронной микроскопии исследована структура стеклоуглерода марки СУ-2000 и выявлены ограничения, налагаемые его структурой, на форму, геометрические размеры и аспектное отношение микроострий, формируемых методом термохимического травления.

\section{Исследование структуры стеклоуглерода}

Стеклоуглерод представляет собой твердый, прочный, изотропный, газонепроницаемый, химически инертный материал, состоящий на 99.99\% из углерода и относящийся к переходной форме углерода. Согласно данным рентгеноструктурного анализа, стеклоуглерод не имеет трехмерного упорядочения и состоит из двух модификаций углерода: тетраэдрической, как у алмаза, и тригональной, как у графита [5]. Структура стеклоуглерода марки СУ-2000 проявляется в процессе формирования микроострий методом термохимического травления.

Исследование структуры СУ-2000 проведено на пластинах размером $20 \times 30 \mathrm{~mm}$ и толщиной $2 \mathrm{~mm}$. Одна из плоскостей $(20 \times 30 \mathrm{~mm})$ была подвергнута термохимическому травлению сплошной пленкой никеля при температуре $1100^{\circ} \mathrm{C}$. В результате травления был получен срез пластины параллельно исследуемой плоскости. На срезе стеклоуглерод представлял собой объемные замкнутые полости размером от 0.5 до $2.5 \mu \mathrm{m} \mathrm{c}$ неправильной в сечении геометрической формой. Полости хаотически распределены по поверхности стеклоуглерода и разделены перегородками толщиной до $1 \mu \mathrm{m}$ (рис. 1,a). При увеличении в 200000 раз (рис. 1,b) видна еще более тонкая структура, также состоящая из объемных полостей размером до $50 \mathrm{~nm}$, разделенных в свою очередь перегородками толщиной $\sim 5 \mathrm{~nm}$. Можно сделать вывод о фрактальном строении поверхности стеклоуглерода СУ-2000.

\section{Формирование матрицы микроострий и обсуждение полученных результатов}

Технологический процесс изготовления матрицы микроострий включал в себя формирование островков из фоторезиста в форме прямой призмы высотой $\sim 1.2 \mu \mathrm{m}$ и основанием в форме квадрата методом фотолитографии, гальваническое осаждение пленки никеля и термохимическое травление. Никель осаждался на поверхность стеклоуглерода, свободную от островков фоторезиста. После удаления фоторезиста в пленке никеля формировались отверстия размером и топологией, как у островков из фоторезиста (рис. 2). Высота формируемых микроострий зависела от толщины пленки никеля, а диаметр вершин - от размера отверстий. При толщине пленки $\sim 0.5 \mu \mathrm{m}$ формировались микроострия высотой

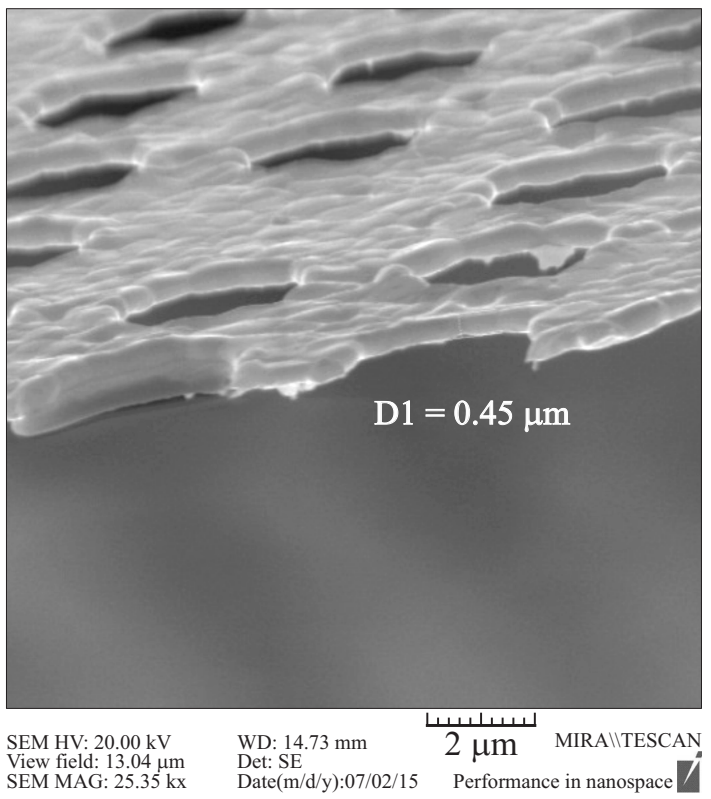

Рис. 2. Пленка никеля с отверстиями.

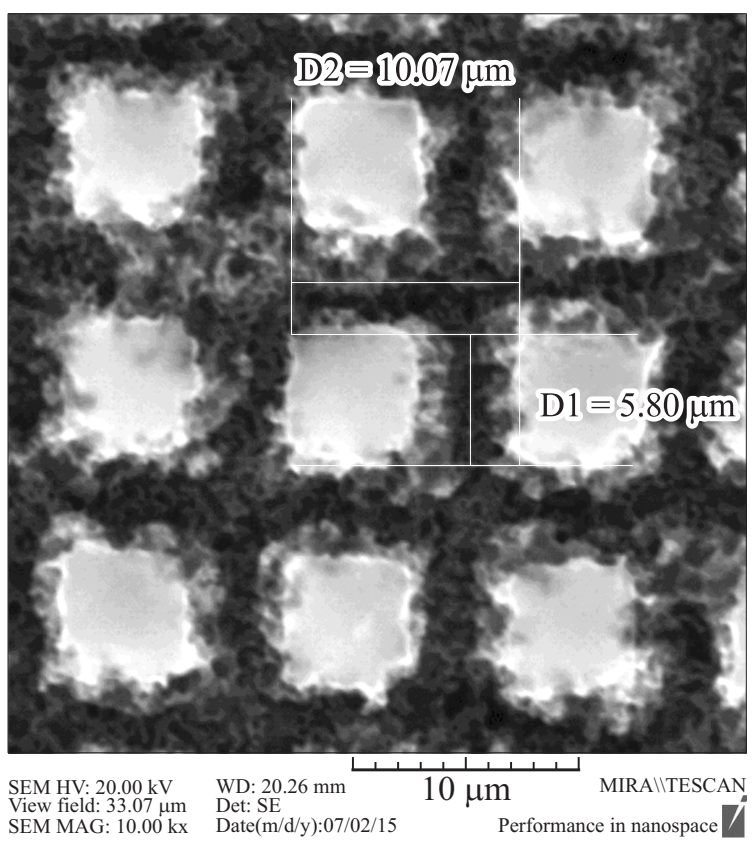

Рис. 3. Матрица микроострий (фотошаблон № 1).

не более $10-12 \mu \mathrm{m}$. Пленки бо́льшей толщины отделялись от поверхности стеклоуглерода из-за недостаточно хорошей адгезии. Таким образом, увеличить аспектное отношение микроострий за счет увеличения их высоты не представлялось возможным.

Были изготовлены матрицы микроострий с использованием фотошаблонов с различными размерами островков фоторезиста и расстояниями между ними. Отверстия в пленке никеля, сформированные по фотошаблону № 1, имели размеры $6 \times 6 \mu \mathrm{m}$ и располагались в углах квадра- 
та со стороной $L=10 \mu \mathrm{m}$, а отверстия, сформированные по фотошаблону № 2, имели размеры $2.2 \times 2.2 \mu \mathrm{m}$. До технологической операции плазмохимического заострения отчетливо видна изрезанность контура вершин микроострий, связанная с наличием полостей (рис. 3). На рис. 4 представлена фотография катодной матрицы после операции плазмохимического заострения. Плотность упаковки микроострий высотой $12 \mu \mathrm{m}$ составила $1 \cdot 10^{6} \mathrm{~cm}^{-2}$. Поверхность вершин имела неправильную

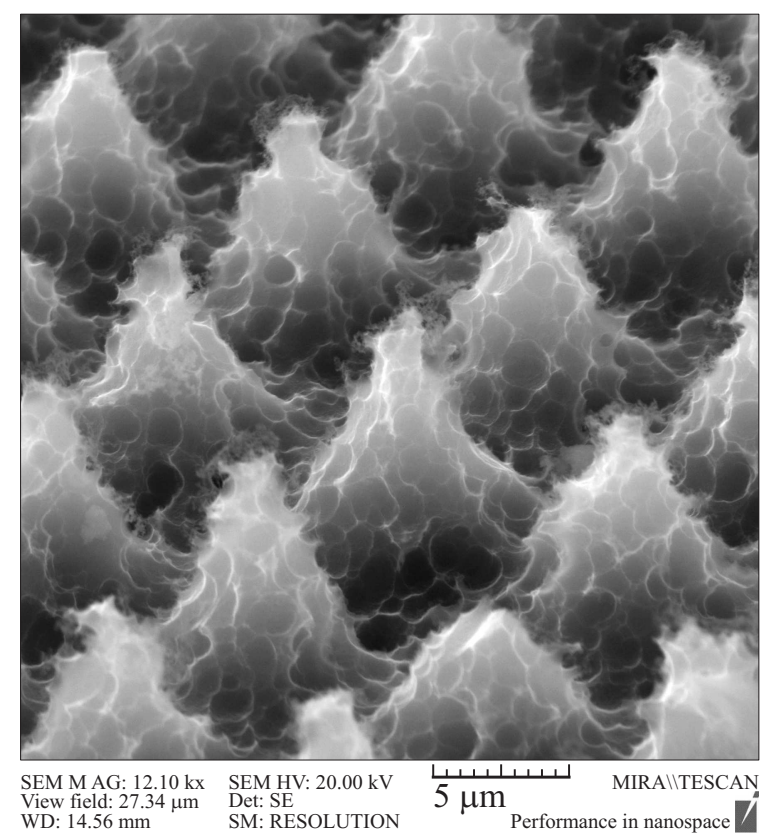

Рис. 4. Матрица микроострий после плазмохимического заострения (фотошаблон № 1).

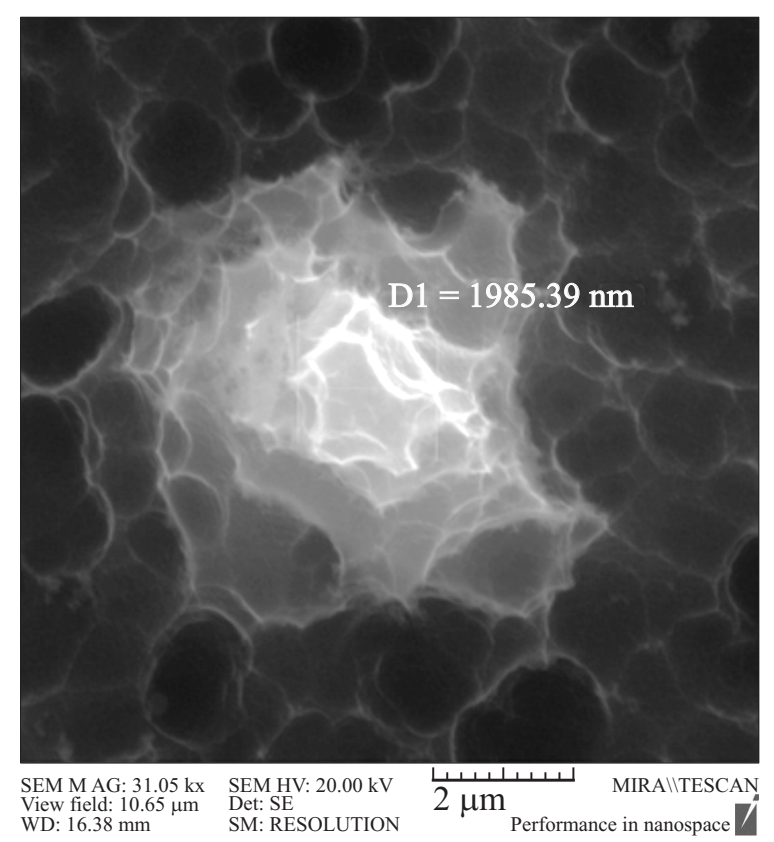

Рис. 5. Микроострие (вид сверху).

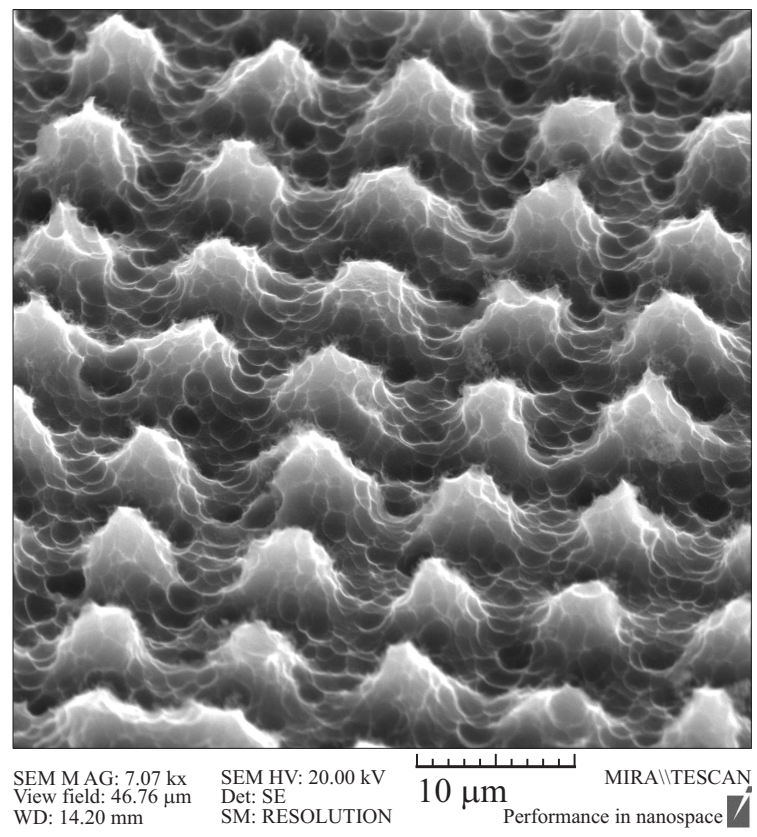

Рис. 6. Матрица микроострий после плазмохимического заострения (фотошаблон № 2).

форму с минимальным размером до $1.6 \mu \mathrm{m}$ (рис. 5). Аспектное отношение не превышало 15 единиц. На рис. 6 приведена фотография катодной матрицы, изготовленная по фотошаблону № 2, после плазмохимического заострения. Плотность упаковки микроострий составляла $\sim 2.8 \cdot 10^{6} \mathrm{~cm}^{-2}$, микроострия не имели ярко выраженной вершины, а их максимальная высота составляла 6-7 $\mu \mathrm{m}$. В процессе термохимического травления там, где отверстия в пленке никеля целиком располагались над полостью на поверхности стеклоуглерода, высота формируемых микроострий уменьшалась на глубину полости. Чем больше был размер полости, тем меньше была высота формируемых микроострий.

Проведенные исследования показали, что объемные полости в стеклоуглероде марки СУ-2000 не позволяют формировать методом термохимического травления матрицы с равновысокими микроостриями с размером вершин менее $1.5-1.6 \mu \mathrm{m}$ и ограничивает их аспектное отношение 10-15 единицами.

Таким образом, для формирования матрицы равновысоких микроострий размер отверстий в пленке никеля должен быть больше размера наибольших по площади полостей, т.е. больше чем $2.5 \mu \mathrm{m}$, а расстояние между вершинами соседних микроострий должно быть более $\sim 5 \mu \mathrm{m}$.

\section{Заключение}

Проведенные исследования показали, что структура стеклоуглерода марки СУ-2000 представляет собой неоднородную структуру, состоящую из объемных образова- 
ний в виде макрополостей неправильной в сечении формы и размером до $2.5 \mu \mathrm{m}$. Объемные полости расположены в теле стеклоуглерода случайным образом и разделены перегородками толщиной до $1 \mu \mathrm{m}$. В свою очередь поверхность макрополостей и перегородок между ними состоит из объемных образований размером до $50 \mathrm{~nm}$, разделенных перегородками толщиной до $5 \mathrm{~nm}$. Таким образом, можно говорить о фрактальном характере поверхности стеклоуглерода марки СУ-2000.

Структура стеклоуглерода марки СУ-2000 накладывает принципиальные ограничения на геометрические размеры, форму и плотность упаковки микроострий катодной матрицы, сформированных методом термохимического травления. Минимальный размер вершин микроострий ограничен размерами полостей в стеклоуглероде. Максимальная плотность упаковки матрицы равновысоких микроострий, которую удалось реализовать с помощью технологии термохимического травления на пластинах из стеклоуглерода марки СУ-2000, составила $1 \cdot 10^{6} \mathrm{~cm}^{-2}$. При этом минимальный размер вершины микроострия не превышал $\sim 1.6 \mu \mathrm{m}$, высота $\sim 12 \mu \mathrm{m}$, а аспектное отношение микроострий не превышало 15 единиц.

\section{Список литературы}

[1] Kosmal H.G. // IEEE Trans. On Electron Devices. 1991. Vol. 38. N 6. P. 1534-1537.

[2] Spindt C.A. // Teth. Digest of 18 th IVNS. Oxford. UK. 2005. P. 20-21.

[3] Григорьев Ю.А., Васильковский С.В., Шестеркин В.И., Яриева 3.А. // Патент № 1738013. 06.04.93.

[4] Бушуев Н.А., Глухова О.Е., Григорьев Ю.А. идр. // ЖТФ. 2016. Т. 86. Вып. 2. С. 134-139.

[5] Фиалков А.С. Углеграфитовые материалы. М.: Энергия, 1979. $319 \mathrm{c}$. 